\title{
What Brings People to Leadership Roles: A Phenomenological Study of Beef Industry Leaders
}

\author{
B. Lynn Gordon, Ph.D. \\ Extension Field Specialist \\ South Dakota State University \\ Sioux Falls, SD \\ lynn.gordon@sdstate.edu \\ Jason D. Ellis, Ph.D. \\ Assistant Professor \\ Kansas State University \\ Manhattan, KS \\ jdellis@ksu.edu
}

\begin{abstract}
Leadership has been deeply studied in the literature; however, little research exists studying the role of volunteer peer leaders in non-formalized leadership roles in membership-based organizations. This phenomenological study was designed to explore the experience of beef industry leaders in leadership roles. Twelve active beef industry volunteer leaders were interviewed and described their experience as leaders. Industry leadership was defined from study themes as a role fulfilled by someone who is willing to serve their industry, with the best of the industry in mind and taking on the responsibility and challenges that come along with making decisions to serve and speak for their peers with integrity. Seven themes identified the central phenomenon and seven traits of beef industry leaders were identified. This study offers significance to the field of leadership; to the beef industry; and to agricultural organizations that may guide developing future leaders.
\end{abstract}

\section{Introduction}

The beef industry is facing some of the most challenging times ever. Intensified competition in the meat case, ever-changing international markets, private interest groups questioning production methods, low prices, high input costs, increased regulations on land, water and food safety issues, aging producers, and policy issues that can impede current production are all providing challenges for the industry (Armbruster, Halbrook, \& Thompson, 2006; Field, 2010; Olynk, Tonsor, \& Wolf, 2010; Otto \& Lawrence, 2001). 
Regulations and specific production practices can be costly for producers to implement, often with little return. In a volatile industry impacted by the political agenda, there is no guarantee grassroots beef producers are protected or their best interests kept in mind in the development or implementation of new legislation. In order to keep one's business viable, the beef industry requires cooperation or minimal interference from local, state and national governments (Catchings \& Wingenbach, 2006).

To represent the needs of the producers to state and national legislative bodies, a unified voice is critical and volunteer association members will be challenged to provide the necessary leadership. There are many people and organizations involved in grassroots issues (Kellogg Foundation, 1993) including agricultural and beef industry organizations.

The role of agricultural organizations is to address issues that will directly and indirectly impact the livelihood of its members. Without solid, dedicated individuals in leadership roles, reaching organizational goals may be limited. Members are the lifeblood of organizations and their leadership, typically on a voluntary basis, is called upon to assist the organization with decision making and setting future goals and vision.

A Kellogg Foundation (1993) study of grassroots leadership determined grassroots leaders are those who share identifiable characteristics to affect change and are motivated and rewarded by their commitment and service. The study concluded that when communities are truly intentional about grassroots leadership many benefits result, such as (a) more people get involved in all levels, (b) new leaders have access to support; a pipeline of new leaders is developed, (c) longterm leaders continue to grow and are renewed, (d) new talent is developed for mainstream leadership positions, and (e) more of a grassroots perspective is present in business, non-profit, and government management.

Research suggests a need for more effective beef industry leadership. Purcell (2002) studied the challenges facing the beef industry and how the industry can address these challenges to survive after an 18-year decline in demand for beef. Purcell's (2002) prescription for a healthy beef industry includes more adequate beef industry leadership.

Beef industry leaders today are challenged to be the voice of their industry during difficult times (Field, 2008; Speer, 2008). This voice comes in the form of volunteers within the industry who serve on committees or boards of industry organizations, such as state or national cattlemen organizations. This volunteer role is vital for the support of the organization and the ability of the organization to 
meet their mission and goals (Mathews \& Carter, 2010). As organizations become more aware of volunteers as a resource and how to efficiently utilize volunteers, organizations have gained interest in ways to improve recruitment, training, motivation, and retention (Handy \& Hustinx, 2009).

Leadership offers advantages for the individuals themselves. Individuals who take on the role of serving on boards or committees commit themselves to participate in a meaningful way and function as a catalyst for change and the result can be a highly rewarding experience. Those willing to take on leadership roles distinguish themselves among their peers and begin the process of developing as true leaders (Korngold, 2006).

Studies focused on current and emerging leaders in the beef industry (Purcell, 2002) and leadership development and education of volunteer leaders in agricultural organizations has only taken place on a limited scale (Mathews \& Carter, 2010; Carter \& Rudd, 2006). In conjunction with a land-grant university or other educational institutions, several states have initiated formal leadership development programs to prepare adult leaders in agriculture; however, these leadership programs focus primarily on leadership skill development (Hejny, 2010). Limited research has been conducted to study what brings a person to leadership, especially leaders in non-formal leadership roles.

\section{Theoretical Framework}

Burns (1978) identified two types of political leadership - transactional and transformational. Transactional leadership occurs when one person takes the initiative in making contact with others for the purpose of an exchange of something that is valued. Leaders will approach followers with a focus on the exchange. Burns (1978) believed that transformational leaders have the ability to elevate followers into leaders. Transformational leadership differs from transactional leadership as it focuses on the personal values and beliefs of the leaders rather than an exchange of items between the leader and follower (Kuhnert \& Lewis, 1987).

Bass (1985) who also studied transformational and transactional leadership described transactional leaders as those focused on achievement of personal or organizational outcomes and transformational leadership as superior leadership performance. In his further comparison of transformational and transactional leadership, Bass (1990a, 1990b) found transformational leaders (a) to be more effective, (b) have better relationships with their supervisors, and (c) make more of a contribution to the organization. In addition, followers exert more effort on behalf of transformational managers than transactional managers. Also, 
transformational leaders are more likely to be viewed as effective leaders than transactional leaders.

Barker (1997) believed there was value in focusing on the abilities and characteristics of leaders because this would be effective for the development of leadership training programs. The most common component across the definitions of leadership is that leadership is an influence process assisting followers (individuals) in reaching a common goal (Northouse, 2010).

An early theory in the field of leadership focused on traits. Stogdill's 1948 and 1974 studies (as cited in Northouse, 2010) were conducted to identify traits that set individuals in leadership roles apart from other average individuals. Northouse summarized the primary traits found in leadership research studies to be intelligence, self-confidence, integrity, determination, and sociability.

With the focus on behavior rather than traits, Kouzes and Posner (2002) developed a model of leadership stemming from their focus on transformational leadership in their attempts to describe a leader. They constructed a model with five fundamental practices of leadership - model the way, inspire a shared vision, challenge the process, enable others to act, and encourage the heart.

In his essay, The Servant as a Leader, Greenleaf (1977) launched a leadership movement wherein great leaders are servants first. Servant leadership is dramatically different than the traditional perspective studied. With servant leadership the focus is (a) involving others in the decision making process, (b) demonstrating a caring, (c) ethical behavior, (d) interest in the growth of employees (followers), and (e)the success and improvement of the organization (Spears, 2010). Based on Greenleaf's (1977) original work, Spears (2010) identified 10 characteristics of a servant leader:

- Listening

- Empathy

- Healing

- Awareness

- Persuasion

- Conceptualization

- Foresight

- Stewardship

- Commitment to growth of people

- Building community 
Most of the research on leadership takes place within the field of organizational development, measuring leadership in a business setting where a manager has oversight over an employee or employees. As a result, the terminology of leader and follower is used as the basis in studying and researching leadership. Transformational, transactional, and servant leadership are all based around the common workplace setting. With limited resources on leadership in a nonformalized setting, this study will open the door for more research in this field.

\section{Volunteer Leaders}

Volunteers are vastly different than employees because they are not rewarded with pay or direct financial benefits for their work (Peters, 2010). About $44 \%$ of volunteers became involved with their main organization after being asked to volunteer, most often by someone in the organization, and $40.9 \%$ became involved due to their own initiative to volunteer (U.S. Bureau of Labor Statistics, 2010). Musick and Wilson (as cited by Handy \& Hustinx, 2009) noted volunteerism is a form of work because it demands skills and competencies. Education was identified as the most consistent and important predictor of volunteering, but other relevant resources were income, occupation, free time, health, gender, and race.

Additional studies focusing on motivation and roles of volunteers used as a framework for this study found the importance of volunteers:

- Understanding their roles to be a determinant in a member's willingness to serve (Carter \& Rudd, 2006; Van Til, 1988).

- Goals being in line with that of the organization (Hinkle, FoxCardamonde, Haseleu, Brown, \& Irwin, 1996; Martinez \& McMullin, 2004).

- Having the opportunity to offer their talents and had a belief they owed their service to their industry (Kajer as cited in Carter \& Rudd, 2005).

While leadership has been extensively studied in the formal organizational development setting, little is known about leadership in non-formal membershipbased organizational settings where individuals are volunteer industry leaders serving their peers.

\section{Purpose}

The purpose of this study was to explore beef industry leaders in formal positions of industry membership organizations. The central research question was: What is 
industry leadership to beef industry leaders? More specifically, the study researched the following sub-questions:

- How do industry leaders characterize industry leadership?

- How do industry leaders explain the process to become an industry leader?

- How do industry leaders describe what influenced them to become leaders within the industry?

\section{Methods}

This study utilized a qualitative approach to explore the phenomenon of beef industry leaders in order to understand industry leadership within the industry. The research relied on interviews of identified individuals using broad, general questions to explore the problem and to learn from the participants, the participants' experience, and how they interpret the experience (Richards \& Morse, 2007; Plano-Clark \& Creswell, 2010). The data was later analyzed to determine themes (Plano-Clark \& Creswell, 2010).

Because the purpose of the study was to understand an essence of the phenomenon (Richards \& Morse, 2007; Hatch, 2002); therefore, a phenomenological qualitative study was chosen from Creswell's (2007) five qualitative study traditions. All participants shared the common experience of the phenomenon as they were volunteer leaders serving in leadership roles for a beef industry organization. Moustakas' (1994) two primary questions to determine the appropriate model were used as a basis to also determine the focus of the study as a phenomenological study. The study sought to gain a greater understanding of the meaning of leadership and what brings people to leadership. Thus, the phenomenological method was the best for seeking to explain and understand leadership in the beef industry.

To provide an acceptable sample size for a qualitative study (Creswell, 2007; Plano-Clark \& Creswell, 2010; Richards \& Morse, 2007), 12 men and women actively serving in leadership roles for beef cattle industry membership organizations were selected to participate in the study. The individuals were intentionally selected. Using homogenous sampling techniques (Creswell, 2008), they were of similar type because all participants were leaders in a beef industry membership organization at the national level. Organizations included either the National Cattlemen's Beef Association or a seed stock beef cattle membership organization such as the American Angus Association. The number of leadership roles was not a determining factor in selecting interview participants; however, they had to be active on at least one committee or board to create similarity across all participants. 
Criteria to differentiate the participants followed maximal variation sampling (Creswell, 2007). Leaders who varied in age, gender, geographical location, and sector of the industry (e.g., seed stock; commercial cow/calf;

backgrounder/stocker or feedlot) were identified. The study aimed for a balance of genders, although had to take into consideration the dominance of men in the agricultural field. Of the 12 participants, nine were male and three were female. They represented 11 different states. There were two seed stock industry representatives, four from the cow/calf segment of the industry, two representing the backgrounder/stocker industry, and four feedlot segment representatives. Strong emphasis was placed on selecting leaders who made their livelihood primarily from the beef cattle industry and were actively involved in production agriculture. Eleven of the participants matched the selection criteria. One participant indicated that in addition to the family's ranching business, the individual was employed in a full-time position in agriculture/livestock production.

A set of broad questions was developed for data collection to elicit broad responses from the participants (Plano-Clark \& Creswell, 2010; Richards \& Morse, 2007). Geographical limitations presented in this study necessitated interviews being conducted via telephone. The interviews averaged 60 minutes in length, ranging from 40 to 90 minutes. All participants were asked the same six questions from the interview protocol form and asked predetermined probing questions (Creswell, 2007). Additional questions were only asked to clarify a point. The interviews were transcribed for coding. Additional notes taken during the interviews were also documented. Collection of data occurred between February 27 and March 10, 2011.

Participants were invited to take part in the research study via an initial email letter explaining the project and then a follow up phone call or email to determine their acceptance to be a participant. The participants were asked to sign the consent form and fax it back to the researcher. The researcher verbally reviewed the consent form with the participant prior to conducting the interview to make sure the participant did not have any final questions about the project. All participants returned the consent form.

The study was pre-approved by the Institutional Review Boards (IRB) of the researchers' universities in order to assure ethical management of the study. All aspects of the study were reported and approved by the appropriate IRB prior to the start of data collection. 


\section{Identifying Themes}

Significant statements and meanings about the phenomenon were analyzed and reported as the themes and what was experienced (Plano-Clark \& Creswell, 2010). To identify themes, the researcher read the 12 verbatim transcripts several times to obtain an overall feeling for the data. Significant phrases and sentences were identified and coded to formulate meanings and were clustered together by common themes (Moustakas, 1994). A rigorous examination of the data was conducted to gain a greater understanding of the central phenomenon. All the themes were in vivo - directly from the interviews of the participants. The transcripts were analyzed using the software program MAXqda. MAXqda. This allowed the researcher to conduct initial coding, highlight quotes, and provide a rich, thick description of the research study participant responses (Creswell, 2007). From the hand-coding for themes and the integration of the software analysis, the results were incorporated into an in-depth description of the phenomenon.

\section{Validating Results}

Because the study was conducted as qualitative research, the focus was on understanding the information expressed by the participants, rather than validations of a quantitative nature. Referencing Creswell's (2007) eight strategies of validation used in qualitative studies, the researcher conducted clarifying researcher bias, member-checking, using rich, thick descriptions, and peer review.

The researcher conducted member checking of the data to validate the results. All participants were provided the opportunity to review the transcripts for validity and credibility and they were asked to make changes or add information. Two of the participants requested to see their interview transcripts, the remaining 10 participants chose not to review the transcripts. Of the two who reviewed the transcripts, one participant contacted the researcher with corrections in spellings and acronyms, the second participant did not indicate any needed changes. Participant names were changed to pseudonyms and any information that could identify the participant was removed or altered so as to be unidentifiable. The format of this study did not allow for the participants to review the other existing data and analysis without breaching confidentiality of the data.

Rich, thick descriptions were used as an additional data validation method. Detailed participant responses to the questions, including direct quotes, were provided in the findings. In the final step of the data analysis, an essence was written to explain the central phenomenon - what the participants experienced and 
how they experienced it. Peer review was conducted by a seasoned academic researcher to further validate the interpretations of the themes and conclusions drawn from the qualitative data by the primary researcher.

\section{Findings}

Using the central question - "What is industry leadership to beef industry leaders?" - for analysis of transcripts and the researcher's notes, the data revealed seven primary themes:

- The world is run by those who show up.

- Represent what is best for the industry.

- Be willing to carry the bucket.

- Gained while giving.

- Have innate leadership abilities.

- A natural progression.

- Selected by your peers.

Theme One: The world is run by those who show up. This was a popular statement heard among the participants. This statement summarized to them that you cannot be a leader if you do not show up or you cannot have a say in the future of the beef industry if your voice is not heard. Those who show up are willing to serve, volunteer, get active, and be dedicated to the future of the industry. If they want to be part of the decisions made impacting the future of the beef industry then they needed to be present for the discussions. For some of the other participants, they did not reference this statement specifically, but they identified the importance of showing up at meetings, taking part, and giving of their time.

Theme Two: Represent what is best for the industry. The participants clearly identified their pride for their role in the beef industry and how seriously they take their role of working with other producers to enhance and impact the future of the industry. They have high expectations of leaders in the beef industry to represent the industry to the best of their ability and for someone who is willing to put the goals of the organization/industry first. The participants also expected this of themselves as they served in a leadership role. The participants believed in order to have confidence in a leader they must feel self-assured that the chosen leader has the best interest of the beef industry at heart.

Theme Three: Be willing to carry the bucket. This statement was made in reference to a leader who is willing to carry the bucket (of water) - regardless of how heavy the bucket may be. The participants emphasized the role of a leader as being a decision-maker. The responsibility of being the decision-maker is a huge 
one as described by the participants. The participants discussed the importance of a leader who can make decisions, even in cases when there are tough or unpopular decisions to be made. In efforts to make these decisions, leaders were described as those who must be able to see the big picture and steer the organization forward. In essence, the leader is challenged to be pushing the envelope and doing this requires taking a stand and making tough decisions.

Theme Four: Gained while giving. The beef industry has been described as an industry that often sees ranches and businesses passed down from generation to generation within families; however, three of the participants indicated they did not grow up in the business they were actively pursuing as their livelihood.

Taking this into consideration, all of the participants expressed the importance of giving back to the industry. Taking the time to volunteer and give back to the industry allowed these participants to gain more and new knowledge, build relationships with fellow beef producers, and have opportunities they would not have experienced otherwise.

Theme Five: Have innate leadership abilities. The leaders described by the study participants had characteristics or traits that were reflective of many strong abilities and characteristics that allowed them to succeed as leaders. Traits recognized were trustworthy, respectful, integrity, responsible, knowledgeable, great listener, and dedicated. They were describing a leader with character and one who displayed effortless and innate abilities that provided that substance of the leader. They were leaders the participants looked up to, but they were also ordinary people who mixed together abilities resulting in personal charisma and that made those in the industry believe and trust in the leader.

Theme Six: A natural progression. It was obvious that being a leader was not on the To Do list of these participants. They did not have a set plan or timeline where they said their goal was to be the president of the state cattlemen's group. Rather, their rise to leadership occurred through a process of natural progression. In all cases, the leaders started to get active in their organizations whether they were recruited or started to volunteer for roles. As their dedication and time commitment grew within the organizations, they found their role snowballing into more and more leadership roles. This theme also related to the second subquestion to identify how the process to leadership occurred.

Theme Seven: Selected by their peers. Several participants mentioned how unique the leadership process is in the beef industry because the leaders are selected by their peers. In typical traditional leadership positions, management selects the leader and the leader then becomes responsible for one or more followers. That is not the case in volunteer membership organizations like state cattlemen or national cattlemen organizations. Rather, leaders are selected by their 
peers to move into leadership roles or in some cases recruited by their fellow association members and asked to serve in a committee or board role. Once in leadership roles, leaders worked with their peers to make industry decisions, and although the responsibility of leading rested on the shoulders of the selected leader, the significant difference in levels of authority as seen in the traditional leader-follower setting does occur with peer leaders.

\section{Traits of a Beef Industry Leader}

The second objective of the study was to determine how industry leaders characterized industry leadership. The first sub-question focused on hearing how participants characterize industry leadership. The participants were asked to define or describe a leader. Responses included terms or phrases like (a) forward thinker, (b) know the facts, (c) accountability, (d) accept the consequences of the decisions, (e) true to their convictions, (f) great listeners, (g) constant communicator, and, (h) be able to work with others. Participants' descriptions of the perfect leader revealed a person with character and integrity; one who they would be proud to say represents their industry. The participants emulated leaders who were respectful and had their heart in the right place (i.e., to represent the industry the best they could). These characteristics allowed participants to trust the leaders, follow them, and have confidence in their ability to make the right decisions and stand by their decisions.

The traits acknowledged in the study led to the identification of seven characteristics of an agricultural leader. Listed in order of emphasis placed by the participants those traits are:

- Willingness to serve

- Decision maker

- Believe in Industry

- Knowledgeable

- Ability to listen/communicator

- Team player/motivator

- Integrity/character

Identifying these traits also provided insight into the fifth theme of the overall study - Have innate leadership abilities.

\section{Sources of Motivation}

The third objective of the study focused on the source of motivation to become a leader. The third sub-question asked, "How do industry leaders describe what influenced them to become leaders within the industry in order to determine their 
motivation to being a leader?" The most common answers were "to give back to the industry that supports their livelihood" and because "they are proud of the industry." Participants were influenced to be leaders because "I care about the industry," "my life depends on it (the industry)," "to get involved and speak up on the issues and out of concern for the future of the industry," and "if it's an industry you are passionate about you want to make it better."

The participants were motivated by a purpose - the purpose to speak up for their industry, to guarantee a future for the next generation, to stand up against outside influences that may be trying to bring the industry down or because their feedlot or ranch has been in the family for generations, and pride has been instilled in them to produce safe, wholesome food. Pride created a purpose as well as concern. If these leaders did not stand up for the industry then who would? Some of the leaders were influenced and encouraged by mentors, some had leadership skills and abilities instilled in them during their tenure in the military, and some had observed leaders who they greatly respected.

\section{Conclusions}

This qualitative study sought to explore leadership traits prevalent in beef industry leaders, identify influences and motivators of the individuals serving in leadership roles for their organizations, and further analyze the structure of the industry and how leaders become leaders in such a setting. A common definition of industry leadership was developed by the researcher. That is, "A role fulfilled by someone who is willing to serve their industry, with the best of the industry in mind and taking on the responsibility, and challenges that come along with making decisions to serve and speak for their peers with integrity."

This study identified qualities and characteristics similar to those found in trait approach research (Stogdill as cited in Northouse, 2010) and were closely aligned to the five central traits identified by Northouse (2010). The participants spoke often about respect, garnering respect, and being respectful. Northouse indicates integrity leads to respect and study data suggest the beef industry leaders have this same interpretation.

Study participants described beef industry leaders as ones who start at the ground level, a trait consistent with servant leadership (Greenleaf, 1977; 1991).

Participants started their involvement in leadership by volunteering and getting active at the local level with beef membership organizations, becoming better equipped to be leaders from the experiences and skills they learned. As the participants discussed their views of leadership, they related very similar thoughts to Spear's (2010) description of servant leaders, which include focusing on others 
in the decision making process, demonstrating a caring and ethical behavior, and interest in the success and improvement of the organization.

Barbuto and Wheeler's (2006) altruistic dimension of servant leadership was identified as one's desire and willingness to serve others and is directly aligned to the first theme identified in the study, "The world is run by those who show up." Beef industry leaders are willing to serve their industry and do so because of the pride and belief they have for their industry and this demonstrates a dimension of servant leadership. The participants' interest in serving because of their altruistic calling was also congruent with what researchers found as to why individuals volunteer. Empowered volunteers have a desire to make a difference (Peters, 2010), which is supported by the findings from this study where beef industry leaders were empowered to step forward and represent the industry to the best of their ability, remembering that their ability to lead impacted not only the industry but the viability of their peers' businesses.

\section{Implications}

Agricultural industry organizations, which are primarily membership-based, are structured to provide members with a legislative voice at the local, state and national level and influence governmental policy (National Grange, 2010). Volunteer leaders fill the roles of committee and board members to represent these organizations. This study offers significance to the field of leadership, to the beef industry, and to agricultural organizations. The beef industry is a viable economic driver for the United States (NASS, 2010). Beef producers rely on beef production for their livelihood and consumers rely on beef for consumption. A greater understanding of industry leadership will provide direction and support to organizations who rely on volunteer leaders to be the decision-makers, facilitators, and representatives of their industry on legislative, economic, social, and production issues.

The results of this study can direct practical implications in the area of leadership and beef industry leader development such as transitioning leadership from one generation to the next, educational leadership training, recruitment and development, clarification of roles for volunteer leaders, the process for volunteers to serve as industry leaders, a greater understanding of leaders in a non-formalized system, and the role of leaders in membership-based organizations.

Insights gained from this study will be most helpful to organizations led by volunteer leaders selected by their peers. This study offers a valuable contribution to the field of research on volunteer peer leaders. Peer leadership is unique to the 
more commonly studied leadership in formalized settings such as in the corporate business world, and this study helps explain why individuals are willing to assume peer leadership roles (i.e., leading their peers) and the expectations of being in a peer leadership role.

This study provides a research basis for beef industry leaders in regards to the trait approach, the styles of leadership (e.g., servant, transformational), sources of motivations, and overall outline of what is industry leadership. Agricultural industry organizations could incorporate some of these foundations discussed and discovered in this study into their organizational structure to aid them in developing and educating leaders, selecting leaders and retaining leaders. 


\section{References}

Armbruster, W. J., Halbrook, S. A., \& Thompson M. M. (2006). Overview: The future of animal agriculture in North America. Choices, 21(3), 153-154.

Barbuto, J. E., \& Wheeler, D. W. (2006). Scale development and construct clarification of servant leadership. Group \& Organization Management, 31(3), 1-27.

Barker, R. A. (1997). How can we train leaders if we do not know what leadership is? Human Relations, 50, 343-362.

Bass, B. M. (1985). Leadership and performance beyond expectations. New York: Free Press.

Bass, B. M. (1990a). Handbook of leadership: Theory, research, and applications ( $3^{\text {rd }}$ ed.). New York: Free Press.

Bass, B. M. (1990b). From transactional to transformational leadership: Learning to share the vision. Organizational Dynamics, 18(3), 19-31.

Burns, J. M. (1978). Leadership. New York: Harper \& Row.

Carter, H. S., \& Rudd, R. D. (2005). Proceedings of 2005 National AAAE Research Conference, Factors Which Influence Leadership Participation in Agricultural Organizations (pp.483-496). San Antonio.

Carter, H. S., \& Rudd, R. D. (2006). Leadership expectations of County Farm Bureau Board Members. Journal of Southern Agricultural Education Research, 56(1), 163. Retrieved from http://www.jsaer.org/pdf/Vol56/5601-163.pdf

Catchings, C. L. \& Wingenbach, G. J. (2006). Texas Agricultural Commodity Board Members' perceptions of the 2002 U.S. Farm Bill. Journal of Extension, 44(1). Retrieved from http://www.joe.org/joe/2006february/rb3.shtml

Creswell, J. W. (2007). Qualitative inquiry and research design: Choosing among five approaches. Thousand Oaks, CA: Sage. 
Creswell, J. W. (2008). Educational research: Planning, conducting and evaluating quantitative and qualitative research. Upper Saddle River, NJ: Pearson Education.

Field, T. (2008). Now's the time for leadership, data. Vision in Action conference. Retrieved from http://www.limousinlive.com/2008/12/field-nows-thetime-for-leadership-data/

Field, T. (2010, September). Perspectives: Outside the box. Angus Journal, 254.

Greenleaf, R. K. (1977). Servant Leadership: A journey into the nature of legitimate power and greatness (pp.7-48). New York: Paulist Press.

Greenleaf, R. K. (1991). The servant as leader. Indianapolis: Robert K. Greenleaf Center. Retrieved from http://www.greenleaf.org/catalog/Introduction_to_Servant_Leadershp .html

Handy, F., \& Hustinx, L. (2009). The why and how of volunteering. Non-profit Management \& Leadership, 19(4), 549-558.

Hatch, J. (2002). Doing qualitative research in educational settings. Albany, NY: State University of New York Press.

Hejny, T. A. (2010). Discovering the leadership skills of alumni who participated in an adult agricultural leadership development program: A case study. Retrieved from http://digitalcommons.unl.edu/cehsdiss/89

Hinkle, S., Fox-Cardamonde, L., Haseleu, J. A., Brown, R., \& Irwin, L. (1996). Grassroots political action as an intergroup phenomenon. Journal of Social Issues, 52(1), 39-51.

Kellogg Foundation (W. K.) (1993). Grassroots leadership development: A guide for grassroots leaders, support organizations and funders. Retrieved from http://www.wkkf.org/knowledgecenter/resources/2003/01/Grassroots-Leadership-Development-A-GuideFor-Grassroots-Leadership-Support-Organizations-And.aspx

Korngold, A. (2006). Developing visionary leaders. Leader to Leader, 40, 45-50. 
Kouzes, J. M., \& Posner, B. Z. (2002). The leadership challenge. ( $3^{\text {rd }}$ ed.). San Francisco: Jossey-Bass.

Kuhnert, K. W., \& Lewis, P. (1987). Transactional and transformational leadership: A constructive/developmental analysis. Academy of Management Review, 12(4), 648-657.

Mathews, C., \& Carter, H. (2010). Proceedings of Association of Leadership Educators (ALE): 2010 ALE Annual Conference Proceedings. Milwaukee, WI.

Martinez, T. A., \& McMullin, S. L. (2004). Factors affecting decisions to volunteer in nongovernmental organizations. Environment and Behavior, 36(1), 112-136.

Moustakas, C. (1994). Phenomenological research methods. Thousand Oaks, CA: Sage National 4-H Organization (2011).

NASS, United States Department of Agriculture. (2010). Overview of the United States cattle industry. Retrieved from http://usda.mannlib.cornell.edu/usda/current/USCatSup/USCatSup-1217-2010.pdf

National Grange History. (2010). The National Grange of the Order of Patrons of Husbandry, History, Founders and Structure. Retrieved http://www.nationalgrange.org/about/history.html

Northouse, P. G. (2010). Leadership, theory and practice $\left(5^{\text {th }}\right.$ ed.). Thousand Oaks, CA: Sage.

Olynk, N. J., Tonsor, G. T., \& Wolf, C. A. (2010). Verifying credence attributes in livestock production. Journal of Agricultural and Applied Economics, 42(3), 439-452.

Otto, D., \& Lawrence, J. D. (2001). Economic impact of the United States beef industry. Retrieved from http://www.beef.org/uDocs/Econ\%20Impact\%20Beef\%20v2.doc

Peters, A. K. (2010). The lived experience of empowered volunteers: A study of Christian church volunteers. Retrieved from http://digitalcommons.unl.edu/aglecdiss/7/ 
Plano-Clark, V. L., \& Creswell, J. W. (2010). Understanding research: A consumer's guide. Saddle River, NJ: Merrill.

Purcell, W. D. (2002, March). Prescriptions for a healthy beef industry. Managing for Today's Cattle Market and Beyond.

Richards, L., \& Morse, J. M. (2007). Readme first for a user's guide to qualitative methods (2nd ed.). Thousand Oaks, CA: Sage.

Spears, L. C. (2010). Character and servant leadership: Ten characteristics of effective, caring leaders. The Journal of Virtues and Leadership, 1(1), 25-30.

Speer, N. C. (2008). 2008 in review. CALF News, 47, 6.

U.S. Bureau of Labor Statistics (2010). Volunteering in the United States, 2009. Retrieved from http://www.bls.gov/news.release/volun.nr0.htm

Van Til, J. (1988). Mapping the third sector, Volunteerism in a changing economy. Journal of Voluntary Action Research, 16(3), 43-53. 


\section{Author Biographies}

B. Lynn Gordon, Ph.D. is an Extension Field Specialist in the livestock industry at South Dakota State University where she conducts program development and communication outreach. She received her doctorate in Human Sciences from the University of Nebraska-Lincoln in May 2011, where she specialized in agricultural leadership studies. She earned her M.S. degree in Business and Marketing Education from the University of Minnesota and her B.S. degree in Agriculture from North Dakota State University. Her career has consisted of extensive work in the field of agriculture and also focused on education, extension, leadership, public relations, and communications. Her current research interests are leadership development in youth and adults as well as effective leadership in organizations.

Jason D. Ellis, Ph.D., Assistant Professor, Kansas State University, deals with food, agriculture, and food safety. He has experience working with food safety in all aspects of the food chain, from producer through foodservice to the consumer. In addition to being a faculty member with the Agricultural Communications and Journalism program at Kansas State University, Jason also has an appointment with the KSU Agricultural Experiment Station where his focus includes effective communications, issues management, and crisis communications to help develop, complement, and maintain a technology transfer system that communicates food safety information. Dr. Ellis has conducted risk communications training both domestically and internationally. He has presented risk communications workshops in nearly every Central and South American country in cooperation with the Inter-American Institute for Cooperation on Agriculture. Prior to joining the faculty at KSU, he was an assistant professor of agricultural journalism at the University of Nebraska-Lincoln for five years. He has worked in marketing communications for animal health companies servicing the beef, dairy, pork, poultry, equine, companion animal, and aquaculture industries. Jason has a B.S. in agricultural journalism and animal science from K-State, a master's degree in meat science, and a doctorate in agricultural education, both from Iowa State University. 